International Journal of Engineering \& Technology, 7 (4.35) (2018) 153-161
International Journal of Engineering \& Technology
SPC
Website: www.sciencepubco.com/index.php/IJET
Research paper

\title{
A Review of Energy Harvesting Methods for Power Transmission Line Monitoring Sensors
}

\author{
Suganthi Yeesparan ${ }^{1 *}$, Mohd Zafri Bin Baharuddin ${ }^{2}$, Norashidah Bt Md Din ${ }^{3}$, Mohamad Halil Haron ${ }^{4}$ \\ ${ }^{I}$ College of Graduate Studies, Universiti Tenaga Nasional, Malaysia \\ ${ }^{2}$ Electronics and Communications Dept., College of Engineering, Universiti Tenaga Nasional, Malaysia \\ ${ }^{3}$ College of Graduate Studies, Universiti Tenaga Nasional, Malaysia \\ ${ }^{4}$ Project Management \& Control Real Estate Ventures Department, Tenaga Nasional Berhad, Malaysia \\ *Corresponding author E-mail: ysuganthi93@gmail.com
}

\begin{abstract}
Condition monitoring sensors have the responsibility of reducing occupational failures or unscheduled shutdowns especially in power transmission line systems. Existing sensors that are used for condition monitoring are mostly battery-dependent. Powering up these sensors in difficult to access areas where high voltage transmission line usually runs is a challenge because batteries usually have a limited life cycle. Power sources other than batteries such as harvesting from solar energy, magnetic energy, radio frequency energy either produces insufficient energy or not entirely available all the time. Electric Field Energy Harvesting (EFEH) overcomes many of these disadvantages and provides a quality and continuous power source to be used to power up devices especially the monitoring sensors that are used in transmission line monitoring. This paper presents key aspects and drawbacks of six types of energy harvesting methods and a review of existing energy harvesters. The concept of electric field and the usage of EFEH in power transmission line system are explained and a comparison between EFEH with typical energy harvesting methods is discussed. This paper finds that EFEH devices have potential to provide sufficient energy for low powered condition monitoring sensors. Moreover, several improved EFEH approaches are proposed, and future trends are discussed.
\end{abstract}

Keywords: Condition Monitoring Sensor, Energy Harvesting, Electric Field, Power Transmission System

\section{Introduction}

Currently, technologies have grown to the extent where it is unstoppable without any boundaries especially in wireless communications and electronics. This enormous growth has made many revolutions on how condition monitoring sensors work. Condition monitoring consist of either manual or automated inspection of the condition of mechanical and electrical devices [1]. Condition monitoring is widely used in observing health of humans, environmental parameters and industrial parameters [2]-[5].

Sensors that are used for condition monitoring have their own advantages where they are easy to be installed even in rural areas along the hills and across the oceans. Condition monitoring sensors have an adaptive behavior to any situation and most importantly it avoids plenty of wiring and can be monitored regionally [6], [7]. Unfortunately, continuously powering up these sensors has been a major challenge where most of them are battery powered sensors. In the case of monitoring the conditions on a transmission line, data is collected and stored at every 0.5 seconds to 25 seconds [8] but it can also be set to provide data in a much larger interval depending on available data bandwidth. It is stated in [9], a $9 \mathrm{~V}$ battery can only be used for 200 hours as the sensors that are used in power transmission line system such as temperature sensors, accelerometer, strain sensors, wind velocity and wind direction sensors and humidity sensors operates in 50 to $500 \mathrm{uW}$ of power with an operating voltage from $3.3 \mathrm{~V}$ to $5 \mathrm{~V}$.

The major disadvantage using battery as power source is it has a fixed and limited energy rating or in another way batteries limited lifetime. Even if a rechargeable battery is used, it still degrades as those batteries will have lower energy density over time and continuous overcharging can damage the battery. Moreover, for lowcost applications the charger can cost much more than the actual product and replacing those batteries is also another time and cost consuming work to be done especially in bigger networks [10]. Therefore, energy harvesting solution can play an important role to support this network.

This paper will give a review of existing energy harvesting methods that have been implemented and suggestion on choosing the most suitable energy harvesting method to charge up condition monitoring smart sensors used in overhead power lines. Section 2 reviews types of energy harvesting methods, how it works and challenges faced by each method. Section 3 focuses on the Electric Field Energy Harvesting (EFEH) as an energy harvesting method for monitoring sensors in transmission line monitoring. The section will end by summarizing the drawbacks of existing EFEH. Further improvisations to the EFEH are explained in Section 4. Finally, Section 5 provides the discussions and conclusions of the review work.

\section{Energy Harvesting Methods for Condition Monitoring Sensors and Its Challenges}

It is proven that the condition monitoring sensor can easily work in transmission grids if it is powered up from available energy from its surrounding environment itself [11]. Figure 1 shows some possible locations of condition monitoring sensors on the trans- 
mission line towers. There are several power sources that can be harvested from high voltage lines which can then be used as an alternative source of energy for the condition monitoring sensors. A vast analysis on the concepts, application and challenges of six main types of environmental energy harvesting is done in this subsection and the next chapter.

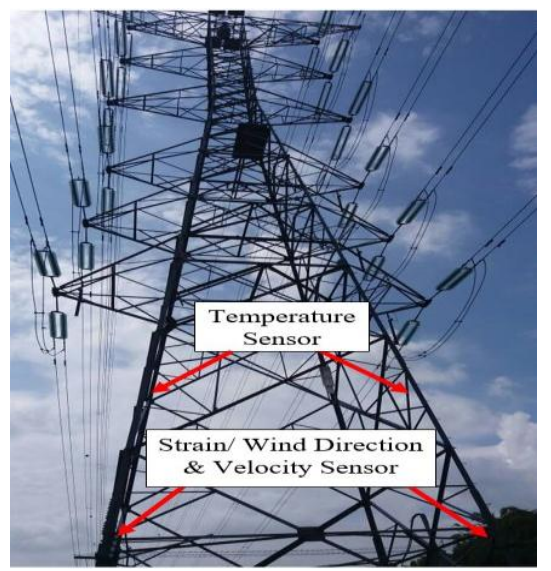

Fig. 1: Possible locations of condition monitoring sensors on a transmission tower.

\subsection{Thermal Energy Harvesting}

Thermal energy harvesting methods can be used on any system or device that produces heat; such as thermal generators, transformers and transmission lines. The operation of a device can cause an increase in temperature and this temperature difference will produce or transmit a natural heat or thermal energy. Seebeck effect found by Thomas Johann Seebeck [12], is the key reference to design a thermal energy harvester where the theory states that voltage can be produced when two different conductive metal intersects at a high thermal point. The voltage produced will increase with respect to the increase of temperature at that point of time [13]. Thermal energy harvesting has been an emerging method between the years 1994 to 2008 as discussed in literature [14] [21]. As an example, Seiko Thermic watch was an initial application that used thermal energy from heat that is produced by humans to run both the watch and also charge an embedded lithiumion battery at $22 \mathrm{uW}$ of power [22], [23].

Thermal energy harvesting looks capable to energize the sensors, however the Carnot cycle limitation is a major disadvantage. The difference in temperature must be high enough to satisfy the Carnot efficiency [22]. A maximum of $16 \%$ efficiency is stated in year 2009 [24] from a thermal generator with a normal resistance of 5 to $10 \mathrm{ohms}$ [25]. A review has reported that even when the thermal generator interface circuit achieved $73 \%$ efficiency, the scavenged power is still very low [26]. Wide environmental temperature difference and the challenges on starting up the harvester have also made thermal energy harvesting to be a less suitable energy harvesting method [27]. From year 2013 till date, the maximum output power level that can be achieved through thermal energy harvesting ranges from $1 \mu \mathrm{W}-100 \mu \mathrm{W}$ [27]-[34]. These literatures using the thermal energy harvesting method show that there is a big challenge to charge up condition monitoring sensors especially in rural areas as a reliable and continuous heat source is not always available. Up to the writing of this review, thermal energy harvesting method has been not being used in transmission line monitoring systems.

\subsection{Solar Energy Harvesting}

Although solar technology was started by Charles Fritts in the 1880's [35], harvesting electricity from the Sun became more matured in the past 20 years. Solar energy harvesting is a process of converting sunlight into electricity using the photovoltaic (PV) process that can then be used as a source of power. [13]. Even though solar energy scavenging has existed for a long time, the concept of utilizing solar power as an energy source for condition monitoring sensors has only been widely used more recently, since around the year 2005 [35]-[38]. One downside of harvesting energy from the sun is that it can only be done when there is daylight. A backup energy storage such as a capacitor or a rechargeable battery is needed to power up the sensors at night. In addition, silicon based PV cells have a typical energy conversion efficiency of around $20 \%$. Studies from year 2007 up till year 2014 not only supports that fact that it is risky to depend on solar energy harvesting due to its low reliability of energy availability but also not worth in terms of installation and maintenance costs [28], [29], [39], [40].

Although a multisource energy harvester including solar is proposed in [41], it is not cost effective. The alternate source used is rechargeable batteries which can lower the energy density of the harvester. Similar studies as above are done and improvised till date in literature [42]-[44]. Although solar energy harvesting is an environmental friendly method and a method that produce a high output voltage up to $600 \mathrm{~mW}$, it is still not always available, has a deployment constraints and not cost effective for a long term condition monitoring sensor applications which is used for transmission line monitoring.

\subsection{Magnetic/Electromagnetic Field Energy Harvest- ing}

Although the concept of magnetic field harvesting was discussed and tested experimentally in 1990 [45], publications on magnetic induction generators became more common much later starting the year 2008. In [46], a magnetic induction generator is used as an energy harvesting device which has a function to measure, use and store the harvested magnetic field energy. Later in 2009, Hubert Zangl introduced a magnetic field scavenging method where energy is captured by running a live conductor through a hollow tube [47]. To support his findings, it has been stated in literature [48] that magnetic field harvesting is most efficient when a ring-shaped core is encased around a high voltage conductor. This can be achieved by using a dissectible donut-shaped core. Even though this energy harvesting method could produce up to 30VA of power from a 150 Ampere live conductor [49], it not practical to clamp the harvesting core around a conductor, as the installation of the harvester requires a major power shut down.

It can be said that the magnetic field energy harvesting method could be an effective technique if the clamping of toroidal core around the conductor is possible [13]. Some example applications of magnetic field harvesting [50], [51] are shown in Figure 2 below.

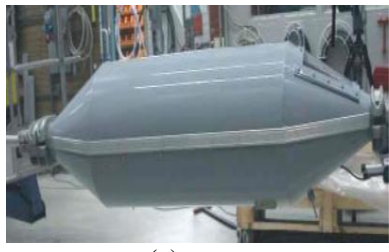

(a)

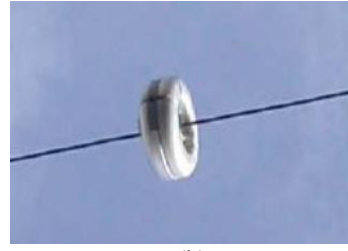

(b)
Fig. 2: (a) PROTURA electromagnetic field harvester [50]; (b) Donutshaped electromagnetic field harvester [51].

Magnetic field energy harvesting not only has a disadvantage of having one of the most complex design to be constructed, but it has a low power rating and also lower energy availability when the source of power is distanced further [28], [52]. The theory of magnetic field strength versus the distance between the source or a live conductor was also proven in [53]-[56], where magnetic field will slowly reduce as the distance between the core is increased. A design of permanent-magnet vibration-based electromagnetic energy harvesters was used in [57] where it used the magnetic 
fields around overhead transmission lines and converted that energy into mechanical vibration via using a small permanent magnet. The device uses an array of several small permanent magnets with opposite polarities to capture power from low-frequency (50/60 $\mathrm{Hz})$ magnetic fields. Although the arrangement of magnets increases the flux gradient, the maximum measured output that they could produce is very low which is around $166 \mu \mathrm{W}$. It is also stated in literature [42] that it is highly unsafe to install the magnetic field energy harvester. Recently in [58], a novel design of magnetic field energy harvester has been designed but it has still a very low output power of $20 \mu \mathrm{W}$.

\subsection{Vibration Energy Harvesting}

Vibration based energy harvesting can be designed from mainly three types of vibration producing devices which are electrostatic, electromagnetic and piezoelectric transducers. These transducers could only produce an output power of $375 \mu \mathrm{W} / \mathrm{cm}^{3}$ which is considered as very limited power [23], [59]-[62]. As shown in [63], vibration energy harvesting is equally compatible with all other energy harvesting methods. On the other hand, an innovative approach was done in [64], [65] where vibration from the core and windings of the transformers are extracted and converted into energy and that energy that can be used to power up condition monitoring sensors. In addition to this application, it is recorded in [66] that the vibration energy harvester could produce $4.5 \mathrm{~mW}$ of power at $132 \mathrm{kV}$.

Vibration energy harvesting has the dual functions of providing power to sensors and at the same time monitoring the devices' conditions. However it can be only function if there is a sufficient amount of vibration force. From this, it can be said that vibration energy harvesting is also source dependent, where its efficiency is solely based on the frequency and magnitude of vibration of the source equipment. A number of similar examples are discussed in [67]-[74].

\subsection{Radio Frequency (RF)/ Electromagnetic Wave En- ergy Harvesting}

Radio frequency (RF) or electromagnetic wave harvesting can be defined as a process that collects accumulated RF signals from tall communication towers and converts the signals to sufficient DC power for the monitoring sensors. The growth of this method of energy harvesting emerged since 2005 [75]. RF energy harvesting method has many advantages where it is convenient in any environmental condition provided that there must be a wide range of good communication networks [13], [76], [77].Various prototype implementations of sensor nodes powered by RF energy are also presented in [78]-[87]. In [88]-[90], a multi-hop RF-powered wireless sensor network is demonstrated through experiments.

RF-powered devices also have attractive healthcare and medical applications such as wireless body network. Benefiting from power generated by RF energy harvesting, low-power medical devices can achieve real-time work-on-demand power and also enables a battery-free circuit with reduced size. Additionally, RF energy harvesting can be used to provide charging capability for a wide variety of low-power mobile devices such as electronic watches, hearing aids, MP3 players, wireless keyboard and mouse, as most of them consume only microwatt to miliwatt range of power [91]. Although RF energy harvesting has many advantages, it cannot function in areas that have no RF source such as deep in the forest where high power transmission line typically runs. Furthermore, RF has relatively very low power density and more importantly RF harvesting methods are distance-dependent [42]. Nevertheless, the usage of this energy harvesting method in [92]-[95] verified that RF energy harvesting is a versatile method especially in urban areas where a lot of RF technology is used.

\subsection{Discussion}

Although the energy harvesting methods explained in this section has its own advantages and disadvantages, each harvesting method plays a good role in providing energy in some specific application. For example, thermal energy harvesting can be applied at an environment which has constant heat supply but it is not efficient in transmission line monitoring systems. Since this paper focuses on methods to power condition monitoring sensors that are used in transmission lines, the next section will discuss the suitability of the EFEH method to scavenge energy and supply it to monitoring sensors on transmission line systems.

\section{Electric Field Energy Harvesting (EFEH)}

Transmission grids and lines act as major parts of an electricity industries as both have to provide a quality electricity supply all the time at an optimized rate and cost. A continuous and dependable power supply is needed for transmission power system condition monitoring sensors such as tilt sensors, strain sensors and temperature sensors to be active all the time. Energy harvesting methods such as solar energy harvesting and thermal energy harvesting cannot provide a continuous supply to sensors networks as there is an availability constraint with a limited source of energy. Alternatively, scavenging energy from the ambient natural environment may prove to be a potential power source for sensor networks in order to avoid the stated problems. EFEH is a promising solution to the shortage of power supply with less limitations as the electric field is always present around the overhead power lines. In this study, few approaches to harvest energy from the electric field around the conductor of high voltage transmission lines to supply low powered monitoring sensors is investigated. Until now, electric field harvesters are only made in a combination of parallel plates or cylindrical capacitors with a simple rectifying circuit [96], [97].

\subsection{How EFEH Works}

In this section, the importance and the suitability of using EFEH in powering up transmission system condition monitoring devices are explained. Sub-section 3.1.1 explains on the basic concept of how electric field is generated. The following section explains on the electric field condition under transmission lines. Sub-section 3.1.3 explains on both the analytical and numerical electric field calculation. Finally, the drawbacks and restriction of the existing EFEH is explained in section 3.2.

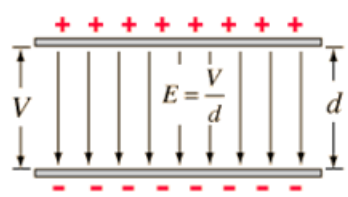

Fig. 3: Electric field between two charged parallel plates.

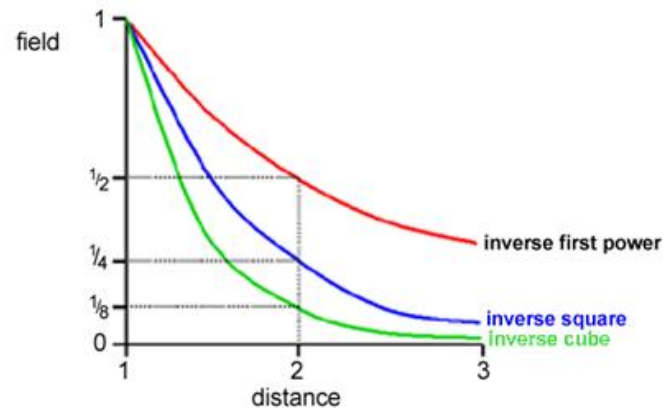

Fig. 4: EMFs range with reference to distance horizontally along the ground [100]. 


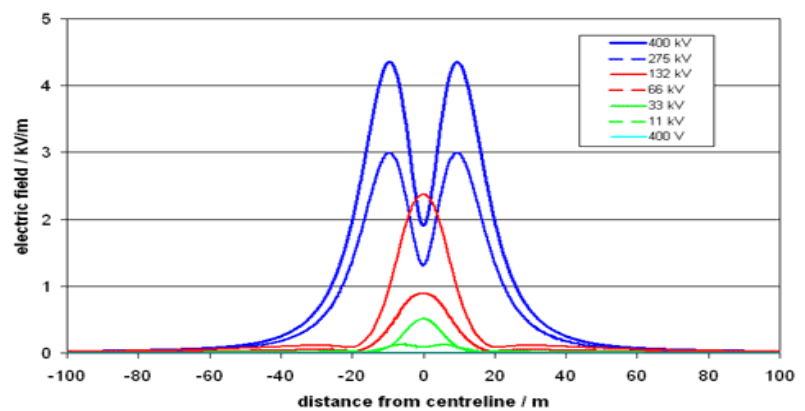

(a)

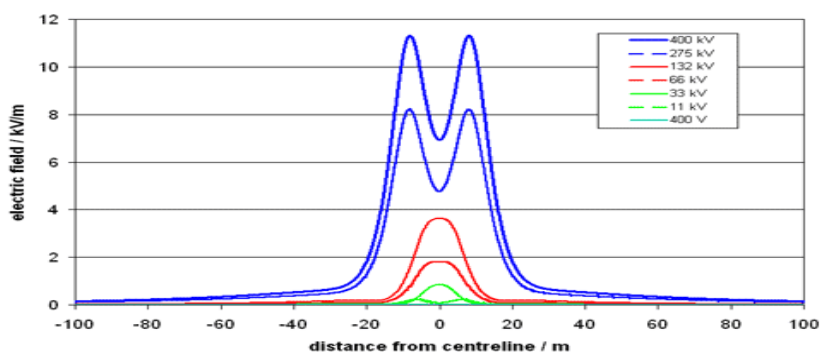

(b)

Fig. 5: (a) Typical electric field of various ranges of overhead transmission line; (b) Maximum electric field of various ranges of overhead transmission line [100].

\subsubsection{Concept of Electric Field}

Electric field is defined as the force in terms of electric that is exerted on a charge [98]. Electric field can be calculated by either dividing electric force in Newtons, $F$, over the charge in Coulombs, $q$, or voltage between plates, $V$, over distance in metres, $d$, between plates. The units for electric field can be measured in Newton/Coulombs (N/C) and also in Volts/Meter (V/m). Electric field is derivable from source potential only if the electric field is in static mode. Those static electric fields can be captured and harvested using a pair of parallel conductive plates of any shape [99] as shown in Figure 3.

\subsubsection{EFEH in Power Transmission System}

Electric field will presumably be constantly available in the surroundings of high voltage transmission line. In this section, the variation of electric field in transmission lines with different voltage ratings is discussed. Electric field from any source usually reduces as the distance from the source increases with reference to the power law. Quite often, this can be approximated as one of three basic types of fall-off with distance as shown in Figure 4. The red line shows the inverse first power distance and referred from single circuit transmission line, the blue line inverse distance squared and referred to power line with un-transposed and transposed phasing, and lastly the green line shows the inverse distance cubed [100].

Figure 5(a) and 5(b) shows the typical and the maximum electric field that can be found at overhead lines. Typical fields are less than maximum fields because the current carried by a line is usually less than the theoretically calculated current. There are many other factors that affects the electric field from the line such as voltage level, amount of clearance, height of the first line to ground, phasing of each line, balancing between and within the circuit and ground resistivity [101].

\subsubsection{Methods to Calculate and Measure Electric Field in Surroundings of Power Transmission System}

Electric field can be calculated using analytical and numerical methods. There are two types of analytical methods which are Maxwell Potential Coefficient Method [101], [102] and the extension of the Maxwell method, which is called Mark and Mengele's
Method [103], [104]. These Maxwell equations for capacities are used to find the electrical charge for the conductor. Using the value of the electrical charge, electric potential and electric field of any point with any distance from the conductor can be calculated [105], [106].

$[U]=[p][q]$

where $[U]$ is the phase potentials in matrix form, $[p]$ is the potential coefficients in matrix form and $[q]$ is electric charge of the conductor. The conductor's charge, $q$ can be found from Eq.1, then the potential voltage at a point $P(X, Y)$ from the overhead power lines can be calculated using:

$V_{P}=\propto \sum_{k=1}^{n} q_{k} \ln \frac{R_{P k I}}{R_{P k}}$

where $R_{P k}$ is the distance between point $P(X, Y)$ and conductor at phase $k$, and $R_{P k I}$ is the distance between point $P(X, Y)$ and the image of conductor at phase $k$. The electric field strength, $E$, at a point $P(X, Y)$ is given as:

$$
\begin{aligned}
& E_{P X}=\propto \sum_{k=1}^{n} q_{k} X_{P k} F_{P k} \\
& E_{P Y}=\propto \sum_{k=1}^{n} q_{k} Y_{P k} F_{P k} \\
& E_{P}=\sqrt{\left(E_{P X}\right)^{2}+\left(E_{P Y}\right)^{2}}
\end{aligned}
$$

where,

$$
\begin{aligned}
& \propto=\frac{1}{2 \pi \varepsilon_{0}} \\
& \varepsilon_{0}=8.854 \times 10^{-12 \mathrm{~F} / \mathrm{m}} \\
& F_{P k}=\frac{1}{{R_{P k}}^{2}}-\frac{1}{{R_{P k I}}^{2}}
\end{aligned}
$$

It is assumed in both the analytical methods that a conductor line is expected to be a line of uniformly distributed charges. As a result, there are many limitations that need to be considered before comparing and referring these methods' results to the numerical results and also the real results.

There are four types of numerical methods that can satisfy the analytical methods stated which are Successive Images Method (SIM) [107]-[109], Charge Simulation Method (CSM) [110][113], Finite Element Method (FEM) and Boundary Element Method (BEM). The level of accuracy of each methods is analysed in [114], [115], it is proved that FEM method complies the closest with the analytical calculation of electric field in surrounding of transmission line. Figure 6 shows an example of FEM modelling using ANSYS Maxwell Software of the electric field under $275 \mathrm{kV}$ lines. The environmental and other restriction is neglected.

\subsubsection{Existing EFEH}

EFEH is the most preferable technique to be used as power source for condition monitoring sensors in overhead transmission line. Table 1 shows a comparison of existing EFEH in high voltage systems since the year 2008. The comparison has been made in terms of some design and performance parameters such as the value of voltage source, the methods used to verify the EFEH, the usage of energy storage device, the harvested output voltage and output power. 
For example, in [97] and [116], the authors have designed an EFEH using two parallel plates with a $330 \mathrm{nF}$ storage capacitor which is attached under a $35 \mathrm{kV}$ line. A sufficient amount of power which is $35 \mathrm{~mW}$ is harvested from the harvester. In [48], [117], $10.6 \mathrm{~mJ}$ energy is harvested without any storage capacitors from a $10 \mathrm{kV}$ source using circular parallel plates. Similar approaches were made in literature [13], [30], [42], [118]-[120], and a maximum of $645 \mathrm{~mW}$ power can be harvested in [120].

In [28], [47], [52], [96], [99], [121]-[126] a toroidal tube made of aluminium or copper is coiled around the conductor line to harvest the electric field energy. This kind approach could scavenge up to $370 \mathrm{~mW}$ [47], [126].

\subsection{Considerations in Designing EFEH Systems}

This section will review the challenges and restrictions faced in existing EFEH methods. These challenges are mainly environmental conditions that might affect the Electric Field harvester and the harvesters' designs in terms of harvester positioning to maximize efficiency. The shape and size of harvesters may also affect the final system output.

All the existing EFEH harvester types reviewed in this manuscript, excluding the harvester in [99], are either attached under the line or coiled around the cable. To install these types of harvesters requires a major power shutdown, which is typically undesirable. An alternative solution for this problem is to locate the harvester at a distance away from the cable source. According to the model in [99], it is proved that the harvester is not necessary to be attached together to the high voltage transmission line. This harvester could produce $0.13 \mathrm{~mW}$ even if the harvester is placed at a safe distance from the line to the ground.

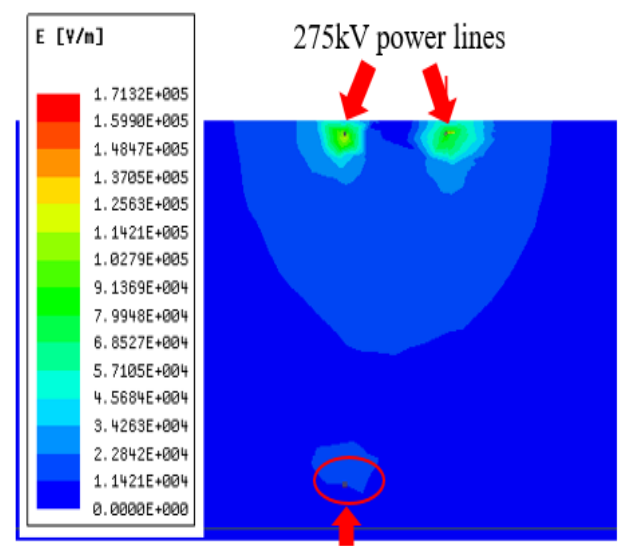

EF energy harvesting plate

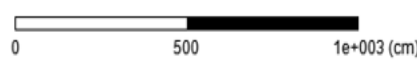

Fig. 6: Example of FEM electric field simulation under $275 \mathrm{kV}$ transmission line using ANSYS Maxwell.
Table 1: Existing EFEH performance comparison

\begin{tabular}{|c|c|c|c|c|c|}
\hline Ref & Volt & Method & Storage & V Out & Power Out \\
\hline$[97],[116]$ & $35 \mathrm{kV}$ & Theo/Sim/Exp* & Cap* & $3-3.1$ & $17 \mathrm{~mW}$ \\
\hline$[48][117]$ & $10 \mathrm{kV}$ & Theo/Sim/Exp & No & NA & $10.6 \mathrm{~mJ}$ \\
\hline$[99]$ & $765 \mathrm{kV}$ & $\begin{array}{c}\text { Theo/Sim/Exp/ } \\
\text { Tested }\end{array}$ & $\begin{array}{c}\text { Storage } \\
\text { cap }\end{array}$ & $3-3.5$ & $0.17 \mathrm{~mW}$ \\
\hline $\begin{array}{c}{[28],[96],} \\
{[124],[127]}\end{array}$ & $60 \mathrm{kV}$ & Theo/Sim/Exp/ & $\begin{array}{c}\text { Super } \\
\text { Cap }\end{array}$ & 3 & $18.8 \mathrm{~mW}$ \\
\hline$[13]$ & $115 \mathrm{kV}$ & Theo/Sim & No & - & $95 \mathrm{~mW}$ \\
\hline$[118]$ & $6 \mathrm{kV}$ & Exp & $\begin{array}{c}\text { Storage } \\
\text { Cap }\end{array}$ & $2.7-3$ & $\begin{array}{c}\text { extremely } \\
\text { low power }\end{array}$ \\
\hline$[126]$ & $150 \mathrm{kV}$ & Exp/Sim & No & 9 & $370 \mathrm{~mW}$ \\
\hline$[47]$ & $60 \mathrm{kV}$ & Sim & No & - & $16 \mathrm{~mW}$ \\
\hline$[121]$ & $12.7 \mathrm{kV}$ & Theo/Sim & No & - & $100 \mathrm{~mW}$ \\
\hline$[123]$ & $50 \mathrm{kV}$ & Exp & No & 30 & $645 \mathrm{~mW}$ \\
\hline$[120]$ & Sim & & & & \\
\hline
\end{tabular}

*Theo- Theoretical, Sim- Simulation, Exp- Experimental, Cap- Capacitor

There is research that designed an EFEH for low voltage lines such as in [121], provided that the harvester is in very close proximity to the voltage source. This EFEH design could only produce a very small amount of energy for the monitoring sensors. However, transmission line sensors need to be located far away from the electric field source to avoid flashovers. At the same time the source needs to provide sufficiently high energy for the EFEH to function. Thus, range of voltages tested and distance to the electric field source are main conditions that need to be considered in designing a suitable EFEH.

Table 2: Existing EFEH designs based on harvester type and position

\begin{tabular}{|l|l|l|}
\hline \multicolumn{1}{|c|}{ Ref } & \multicolumn{1}{c|}{ Harvester Type } & \multicolumn{1}{c|}{ Harvester Position } \\
\hline$[97][116]$ & 2 Parallel Plates & Attached Under the Line \\
\hline$[48][117]$ & 2 Circular Plates & Under/near the Line \\
\hline$[99]$ & $\begin{array}{l}\text { Plastic Tube Enclosed } \\
\text { with Aluminum Foil }\end{array}$ & $30-32.5 \mathrm{~m}$ from Line \\
\hline $\begin{array}{l}{[28],[96],} \\
{[124],} \\
{[127]}\end{array}$ & $\begin{array}{l}\text { Cylindrical Elec- } \\
\text { trode/Tube }\end{array}$ & Around the Conductor \\
\hline$[13]$ & 2 Parallel Plates & Attached Under the Line \\
\hline$[125]$ & $\begin{array}{l}\text { Cylindrical Copper Sheet } \\
\text { around insulated cable }\end{array}$ & $\begin{array}{l}\text { Attached Around the } \\
\text { Line }\end{array}$ \\
\hline$[118]$ & $\begin{array}{l}\text { Copper Plate under the } \\
\text { Line }\end{array}$ & Near to line \\
\hline$[126][47]$ & Cylindrical Electrode & Around the Line \\
\hline$[121][52]$ & Harvesting Tube & Around the Line \\
\hline$[119]$ & 2 Parallel Plates & Near the line \\
\hline$[122]$ & Cylindrical Al Foil & Around the Line \\
\hline$[123]$ & Cylindrical Al Electrode & Around the Line \\
\hline$[120]$ & Plate & Near the Line \\
\hline$[30][42]$ & Plate & Attached with Light \\
\hline
\end{tabular}

Table 3: The Actual Measurement of Electric Field $8 \mathrm{~m}$ under a $275 \mathrm{kV}$ double-circuit transmission line in Selangor Malaysia

\begin{tabular}{|c|c|c|c|c|c|c|c|c|c|c|c|}
\hline Trial & 1 & 2 & 3 & 4 & 5 & 6 & 7 & 8 & 9 & 10 & Average $(\mathrm{kV} / \mathrm{m})$ \\
\hline Day 1 & 5.906 & 5.969 & 5.919 & 5.932 & 5.894 & 5.932 & 5.957 & 5.765 & 5.704 & 5.767 & 5.8745 \\
\hline Day 2 & 6.159 & 5.995 & 6.336 & 6.324 & 6.096 & 6.210 & 5.734 & 5.716 & 5.691 & 5.805 & 6.0066 \\
\hline Day 3 & 5.881 & 5.932 & 5.666 & 5.780 & 5.754 & 5.641 & 5.527 & 5.565 & 5.501 & 5.691 & 5.6938 \\
\hline
\end{tabular}

Table 2 divides several EFEH into two important parameters which are; harvester type where it defines on how the harvesters are designed with respect to its shape, and harvester position with reference to distance from the power source. These designs are all in the form of parallel plates or cylindrical tubes.

As a proof of concept to harvest energy from a high voltage transmission line at a safe distance, electric field measurements were made 8 meters below a $275 \mathrm{kV}$ transmission line in Malaysia for 3 consecutive days. Ten measurements were taken each day at the exact same position. Table 3 shows the results of these measurements. On average the electric field detected is $5.86 \mathrm{kV} / \mathrm{m}$. The- se results prove that sufficient amount of electric field exists at a safe distance away. It is expected that this can be harvested to power up low power monitoring sensors [99].

\section{Improvements to EFEH}

The previous sections have presented an extensive review on energy harvesting method and specifically on applying EFEH in powering up transmission line monitoring sensors. The EFEH method can be improved as proposed below: 
a) Non-contact energy harvesters are proposed as they are easier to install compared to contact-based harvesters.

b) The shape of the harvester plate can be modified from a flat surface to a sharper shape such as a pear shaped conducting plate which will accumulate and capture more electric charge compared to a normal rectangular, cylindrical or circle shaped plate [128]. Investigation into different shapes of the harvester plate may yield better harvesting output.

c) Next generation energy harvesters can be combined with a novel rectifying circuit design to get an improved DC output, which earlier reviews have not emphasized.

\section{Conclusion}

There are many challenges that need to be addressed in all the energy harvesting methods mentioned in this paper. For example, the harvested power from thermal, vibration and RF are not only source-dependent but also limited to rural areas. Solar energy harvesting can only provide supply when there is sunlight. With that we can conclude that all thermal, vibration, RF and solar energy harvesting methods are not suitable to provide continuous power for transmission line monitoring sensors.

Although existing electromagnetic field and electric field energy harvesting methods look promising in terms of fitting into the high voltage transmission line environment, it has some disadvantages too. Most of these types of harvesters are designed in a way that they have to be attached to the line, which makes the installation process difficult and time consuming. Installation and maintenance costs are also high as it requires a major power shutdown and this may interrupt power supplied to the consumers.

As a conclusion, an improved EFEH method is the most suitable method to be used to power up transmission line monitoring sensors. For future developments, a novel non-contact based EFEH method is expected to safely harvest energy at a distance from the transmission line. An enhanced rectifying circuit can be developed to get an improved dc output and higher power conversion efficiency. Changing the shape of the harvesting plate is also possible future work that can be done to provide comparative and qualitative results.

\section{Acknowledgement}

The support and encouragement received from TNB Grid Division, Universiti Tenaga Nasional and UNITEN R\&D Sdn. Bhd. under the funding from the "Research on Radio Frequency Energy Harvesting System for Powering Low Power Devices in A Locality", project: U-TS-RD-17-07, are much appreciated and acknowledged.

\section{References}

[1] R. Bogue, "Sensors for condition monitoring: A review of technologies and applications," Sens. Rev., vol. 33, no. 4, pp. 295299, 2013.

[2] J. K. Hart and K. Martinez, "Environmental Sensor Networks: A revolution in the earth system science?," Earth-Science Rev., vol. 78, no. 3-4, pp. 177-191, 2006.

[3] A. Tiwari, P. Ballal, and F. L. Lewis, "Energy-efficient wireless sensor network design and implementation for condition-based maintenance," ACM Trans. Sens. Networks, vol. 3, no. 1, p. 1-es, 2007.

[4] T. O'Donovan, J. O'Donoghue, C. Sreenan, D. Sammon, P. O'Reilly, and K. A. O'Connor, "A context aware wireless body area network (BAN)," Pervasive Comput. Technol. Heal. 2009. PervasiveHealth 2009. 3rd Int. Conf., pp. 1-8, 2009.

[5] V. Peiris, Highly integrated wireless sensing for body area network applications. 2013

[6] S. Pal, D. Bhattacharyya, G. S. Tomar, and T. Kim, "Wireless Sensor Networks and Its Routing Protocols: A Comparative Study," 2010 Int. Conf. Comput. Intell. Commun. Networks, pp. 314-319,
2010.

[7] P. Tiwari, V. P. Saxena, R. G. Mishra, and D. Bhavsar, "Wireless Sensor Networks: Introduction, Advantages, Applications and Research Challenges Introduction to Wireless Networks," HCTL Open Int. J. Technol. Innov. Res. ISBN, vol. 14, no. April, pp. 2321-1814, 2015.

[8] K. S. Hung et al., "On Wireless Sensors Communication for Overhead Transmission Line Monitoring in Power Delivery Systems," 2010 First IEEE Int. Conf. Smart Grid Commun., pp. 309-314, 2010

[9] Y. Yang, G. Xie, X. Xu, and Y. Jiang, “A monitoring system design in transmission lines based on wireless sensor networks," Energy Procedia, vol. 12, pp. 192-199, 2011.

[10] A. T. I. Fayeez, V. R. Gannapathy, I. S. Md Isa, M. K. Nor, and N. L. Azyze, "Literature review of battery-powered and solar-powered wireless sensor node," ARPN J. Eng. Appl. Sci., vol. 10, no. 2, pp. 671-677, 2015

[11] M. Zhu, M. D. Judd, and P. J. Moore, "Energy harvesting in substations for powering autonomous sensors," Proc. - 2009 3rd Int. Conf. Sens. Technol. Appl. SENSORCOMM 2009, pp. 246-251, 2009.

[12] S. Blundell and K. M. Blundell, Concepts in Thermal Physics. OUP Oxford, 2010.

[13] R. Moghe, Yi Yang, F. Lambert, and D. Divan, "A scoping study of electric and magnetic field energy harvesting for wireless sensor networks in power system applications," 2009 IEEE Energy Convers. Congr. Expo., pp. 3550-3557, 2009.

[14] J. H. Kiely, D. V Morgan, and D. M. Rowe, "The design and fabrication of a miniature thermoelectric generator using MOS processing techniques," Meas. Sci. Technol., vol. 5, no. 2, p. 182, 1994.

[15] M. Stordeur and I. Stark, "Low power thermoelectric generatorself-sufficient energy supply for micro systems," in Thermoelectrics, 1997. Proceedings ICT '97. XVI International Conference on, 1997, pp. 575-577.

[16] I. Stark and M. Stordeur, "New micro thermoelectric devices based on bismuth telluride-type thin solid films," in Thermoelectrics, 1999. Eighteenth International Conference on, 1999, pp. 465-472.

[17] V. Peiris et al., "Energy harvesting for wireless communication systems using thermogenerators," in SPIE Newsroom, 2006, vol. 58 no. 7 , pp. 2597-2604.

[18] G. Savelli et al., "Energy Conversion Using New Thermoelectric Generator," no. April, pp. 26-28, 2006.

[19] H. A. Sodano, G. E. Simmers, R. Dereux, and D. J. Inman, "Recharging Batteries using Energy Harvested from Thermal Gradients," J. Intell. Mater. Syst. Struct., vol. 18, no. 1, pp. 3-10, Oct. 2006.

[20] I. Stark, "Invited Talk: Thermal Energy Harvesting with Thermo Life," in International Workshop on Wearable and Implantable Body Sensor Networks (BSN’06), 2006, pp. 19-22.

[21] L. Mateu, C. Codrea, N. Lucas, M. Pollak, and P. Spies, "Human Body Energy Harvesting Thermogenerator for Sensing Applications," in 2007 International Conference on Sensor Technologies and Applications (SENSORCOMM 2007), 2007, pp. 366-372.

[22] M. Kishi et al., "Micro thermoelectric modules and their application to wristwatches as an energy source," in Thermoelectrics, 1999. Eighteenth International Conference on, 1999, pp. 301-307.

[23] J. A. Paradiso and T. Starner, "Energy scavenging for mobile and wireless electronics," IEEE Pervasive Comput., vol. 4, no. 1, pp 18-27, 2005.

[24] C. B. Vining, "An inconvenient truth about thermoelectrics," Nat. Mater., vol. 8, p. 83, Feb. 2009.

[25] "Tellurex Corporation," 2012. [Online]. Available: http://www.tellurex.com. [Accessed: 11-Feb-2018].

[26] P. S. Weng, H. Y. Tang, P. C. Ku, and L. H. Lu, "50 mV-Input Batteryless Boost Converter for Thermal Energy Harvesting," IEEE J. Solid-State Circuits, vol. 48, no. 4, pp. 1031-1041, 2013.

[27] M. Alhawari, B. Mohammad, H. Saleh, and M. Ismail, "A survey of thermal energy harvesting techniques and interface circuitry," Proc. IEEE Int. Conf. Electron. Circuits, Syst., pp. 381-384, 2013.

[28] X. Zhao, T. Keutel, M. Baldauf, and O. Kanoun, "Energy harvesting for a wireless-monitoring system of overhead highvoltage power lines," IET Gener. Transm. Distrib., vol. 7, no. 2, pp. $101-107,2013$

[29] L. Hou and S. Tan, "A Preliminary Study of Thermal Energy Harvesting for Industrial Wireless Sensor Networks,” pp. 386-390, 2016. 
[30] O. Cetinkaya and O. B. Akan, "Electric-Field Energy Harvesting from Lighting Elements for Battery-Less Internet of Things," IEEE Access, vol. 5, pp. 7423-7434, 2017.

[31] J. Katic, S. Rodriguez, and A. Rusu, "A High-Efficiency Energy Harvesting Interface for Implanted Biofuel Cell and Therma Harvesters," IEEE Trans. Power Electron., vol. 33, no. 5, pp. 1-1, 2017.

[32] K. Le, L. Pham-Nguyen, and S. G. Lee, "An ultra-low-voltagestartup circuit for thermal energy harvesting application," in 2017 7th International Conference on Integrated Circuits, Design, and Verification (ICDV), 2017, pp. 28-32.

[33] A. M. Abdal-kadhim, "Application of Thermal Energy Harvesting from Low-Level Heat Sources in Powering up WSN Node," 2017.

[34] M. Yun, E. Ustun, P. Nadeau, and A. Chandrakasan, "Thermal Energy Harvesting for Self-Powered Smart Home Sensors," pp. 1-4 2016.

[35] G. Meyers, "Photovoltaic Dreaming 1875-1905: First Attempts At Commercializing PV," 2014. [Online]. Available: https://cleantechnica.com/2014/12/31/photovoltaic-dreaming-firstattempts-commercializing-pv/.

[36] V. Raghunathan, A. Kansal, J. Hsu, J. Friedman, and M. Srivastava, "Design considerations for solar energy harvesting wireless embedded systems," in IPSN 2005. Fourth International Symposium on Information Processing in Sensor Networks, 2005., 2005, pp. 457-462.

[37] B. A. Warneke et al., "An autonomous $16 \mathrm{~mm} 3$ solar-powered node for distributed wireless sensor networks," in Proceedings of IEEE Sensors, 2002, vol. 2, pp. 1510-1515 vol.2.

[38] S. Roundy, B. P. Otis, Y.-H. Chee, J. M. Rabaey, and P. Wright, A 1.9GHz RF Transmit Beacon using Environmentally Scavenged Energy, vol. 4. 2003.

[39] C. Bernauer et al., Temperature measurement on overhead transmission lines (OHTL) utilizing surface acoustic wave (SAW) sensors. 2007

[40] M. M. Abbas et al., "Solar Energy Harvesting and Management in Wireless Sensor Networks," Int. J. Distrib. Sens. Networks, vol. 2014, 2014.

[41] Y. Li and R. Shi, "An intelligent solar energy-harvesting system for wireless sensor networks," Eurasip J. Wirel. Commun. Netw., vol. 2015, no. 1, pp. 1-12, 2015.

[42] O. Cetinkaya and O. B. Akan, "Electric-Field Energy Harvesting in Wireless Networks," IEEE Wirel. Commun., vol. 24, no. 2, pp. 34 41, 2017.

[43] C. Wang, J. Li, Y. Yang, F. Ye, C. Engineering, and S. Brook, "Combining Solar Energy Harvesting with Wireless Charging for Hybrid Wireless Sensor Networks," vol. 17, no. 3, pp. 560-576, 2016.

[44] P. Mekikis, E. Kartsakli, A. Antonopoulos, L. Alonso, and C. Verikoukis, "Connectivity Analysis in Clustered Wireless Sensor Networks Powered by Solar Energy," IEEE Trans. Wirel. Commun. vol. 1276, no. DC, 2018.

[45] N. D. Sadanandan and A. H. Eltom, "Power donut system laboratory test and data analysis," IEEE Southeastcon'90. Proceedings., pp. 675-679, 1990

[46] P. M. Glatz, P. Meyery, A. Janekz, T. Trathniggx, C. Steger, and R. Weissk, "A measurement platform for energy harvesting and software characterization in WSNs," 2008 1st IFIP Wirel. Days, WD 2008, 2008

[47] H. Zangl, T. Bretterklieber, and G. Brasseur, "A feasibility study on autonomous online condition monitoring of high-voltage overhead power lines," IEEE Trans. Instrum. Meas., vol. 58, no. 5, pp. 17891796, 2009.

[48] M. Zhu, P. C. Baker, N. M. Roscoe, M. D. Judd, and J. Fitch, "Alternative power sources for autonomous sensors in high voltage plant," 2009 IEEE Electr. Insul. Conf. EIC 2009, no. June, pp. $36-$ 40, 2009.

[49] “30_OTLM-ANGLESKI.pdf." [Online]. Available: http://www.cg.si/wp-content/uploads/2016/08/30_OTLM-ANGLESKI.pdf. [Accessed: 12-Feb-2018].

[50] "Protura [Online]." [Online]. Available: http://www.protura.no/power-line-sensor-0.html. [Accessed: 12Feb-2018]

[51] "USi [Online]." [Online]. Available: http://www.usi-power.com/. [Accessed: 12-Feb-2018].

[52] F. Guo, H. Hayat, and J. Wang, "Energy harvesting devices for high voltage transmission line monitoring," 2011 IEEE Power Energy Soc. Gen. Meet., vol. 43210, pp. 1-8, 2011.

[53] P. Li, Y. Wen, C. Jia, and X. Li, "A Magnetoelectric Composite
Energy Harvester and Power Management Circuit," IEEE Trans. Ind. Electron., vol. 58, no. 7, pp. 2944-2951, 2011.

[54] X. Jiang, Y. Li, and J. Li, Design of a Novel Linear Permanent Magnet Vibration Energy Harvester. 2013.

[55] P. Zeng and A. Khaligh, "A Permanent-Magnet Linear Motion Driven Kinetic Energy Harvester," IEEE Trans. Ind. Electron., vol. 60, no. 12, pp. 5737-5746, 2013.

[56] S. A. Ghani, M. S. Ahmad Khiar, I. S. Chairul, M. Y. Lada, and N H. Rahim, "Study of magnetic fields produced by transmission line tower using finite element method (FEM)," 2014 2nd Int. Conf. Technol. Informatics, Manag. Eng. Environ., no. 2, pp. 64-68, 2014

[57] T. Hosseinimehr and A. Tabesh, "Magnetic Field Energy Harvesting from AC Lines for Powering Wireless Sensor Nodes in Smart Grids," Ieee Trans. Ind. Electron., vol. 63, no. 8, pp. $4947-$ 4954, 2016.

[58] F. Lofink et al., "Magnetically driven energy-harvester with monolithically integrated high-energy-density magnets," 19 th Int. Conf. Solid-State Sensors, Actuators Microsystems, vol. 1, pp. 351-354, 2017

[59] K. W. H, "Piezoelectric energy converter for electronic implants." Google Patents, 1969.

[60] P. Glynne-Jones, S. P. Beeby, and N. M. White, "Towards a piezoelectric vibration-powered microgenerator," IEE Proc. - Sci. Meas. Technol., vol. 148, no. 2, pp. 68-72, 2001.

[61] M. El-hami et al., "Design and fabrication of a new vibration-based electromechanical power generator," Sensors Actuators A Phys., vol. 92, no. 1, pp. 335-342, 2001.

[62] M. Miyazaki et al., "Electric-energy generation using variablecapacitive resonator for power-free LSI: efficiency analysis and fundamental experiment," in Low Power Electronics and Design, 2003. ISLPED '03. Proceedings of the 2003 International Symposium on, 2003, pp. 193-198.

[63] S. Roundy et al., "Improving power output for vibration-based energy scavengers," IEEE Pervasive Comput., vol. 4, no. 1, pp. 28 $36,2005$.

[64] B. Garcia, J. C. Burgos, and A. M. Alonso, "Transformer tank vibration modeling as a method of detecting winding deformationspart I: Theoretical Foundation," IEEE Trans. Power Deliv., vol. 21, no. 1, pp. 164-169, 2006.

[65] B. Garcia, J. C. Burgos, and A. M. Alonso, "Transformer tank vibration modeling as a method of detecting winding deformationspart II: experimental verification,” Power Deliv. IEEE Trans., vol. 21, no. 1, pp. 164-169, 2006.

[66] Perpetuum Ltd, "Perpetuum PMG17 Datasheet," 2008. [Online]. Available: https://perpetuum.com/. [Accessed: 12-Feb-2018].

[67] C. B. Williams and R. B. Yates, "Analysis of a micro-electric generator for microsystems," Sensors Actuators A Phys., vol. 52, no. 1 , pp. 8-11, 1996

[68] S. Meninger, J. O. Mur-Miranda, R. Amirtharajah, A. Chandrakasan, and J. H. Lang, "Vibration-to-electric energy conversion," IEEE Trans. Very Large Scale Integr. Syst., vol. 9, no. 1, pp. 64-76, 2001.

[69] M. Goldfarb and L. D. Jones, "On the Efficiency of Electric Power Generation With Piezoelectric Ceramic," J. Dyn. Syst. Meas. Control, vol. 121, no. 3, pp. 566-571, Sep. 1999.

[70] N. G. E. and A. A. E. and M. Spector, "A self-powered mechanical strain energy sensor," Smart Mater. Struct., vol. 10, no. 2, p. 293, 2001.

[71] R. Amirtharajah and A. P. Chandrakasan, "Self-powered signal processing using vibration-based power generation," IEEE J. SolidState Circuits, vol. 33, no. 5, pp. 687-695, 1998.

[72] H. A. Sodano, D. Leo, and D. Inman, Use of piezoelectric energy harvesting devices for charging batteries. 2003.

[73] E. Leland, R. White, and P. K Wright, "Energy scavenging power sources for household electrical monitoring," Feb. 2006.

[74] S. R. and P. K. Wright, "A piezoelectric vibration based generator for wireless electronics," Smart Mater. Struct., vol. 13, no. 5, p. $1131,2004$.

[75] M. Mi, M. H. Mickle, C. Cape, and H. Switf, "RF Energy Harvesting with Multiple Antennas in the Same Space," IEEE Antennas Propag. Mag., vol. 47, no. 5, pp. 100-105, 2005

[76] O. B. Akan, M. T. Isik, and B. Baykal, "Wireless passive sensor networks," IEEE Commun. Mag., vol. 47, no. 8, pp. 92-99, 2009.

[77] S. Sudevalayam and P. Kulkarni, "Energy Harvesting Sensor Nodes: Survey and Implications," IEEE Commun. Surv. Tutorials, vol. 13, no. 3, pp. 443-461, 2011.

[78] G. Papotto, F. Carrara, A. Finocchiaro, and G. Palmisano, “A 90 nm CMOS 5-Mbps Crystal-Less RF-Powered Transceiver for 
Wireless Sensor Network Nodes," IEEE J. Solid-State Circuits, vol. 49 , no. 2, pp. 335-346, 2014.

[79] H. Nishimoto, Y. Kawahara, and T. Asami, "Prototype implementation of ambient RF energy harvesting wireless sensor networks," in 2010 IEEE Sensors, 2010, pp. 1282-1287.

[80] Z. Popović, E. A. Falkenstein, D. Costinett, and R. Zane, "LowPower Far-Field Wireless Powering for Wireless Sensors," Proc. IEEE, vol. 101, no. 6, pp. 1397-1409, 2013.

[81] D. Dondi, S. Scorcioni, A. Bertacchini, L. Larcher, and P. Pavan, "An autonomous wireless sensor network device powered by a RF energy harvesting system," in IECON 2012 - 38th Annual Conference on IEEE Industrial Electronics Society, 2012, pp. $2557-2562$.

[82] D. Pavone, A. Buonanno, M. D’Urso, and F. Della Corte, Design Considerations for Radio Frequency Energy Harvesting Devices, vol. 45. 2012.

[83] F. Zhang et al., "A batteryless $19 \mu \mathrm{W}$ MICS/ISM-band energy harvesting body area sensor node SoC," Dig. Tech. Pap. - IEEE Int. Solid-State Circuits Conf., vol. 55, pp. 298-299, 2012.

[84] A. Al-Khayari, H. Al-Khayari, S. Al-Nabhani, M. M. BaitSuwailam, and Z. Nadir, "Design of an enhanced RF energy harvesting system for wireless sensors," in 2013 7th IEEE GCC Conference and Exhibition (GCC), 2013, pp. 479-482.

[85] M. Al-Lawati, M. Al-Busaidi, and Z. Nadir, "RF energy harvesting system design for wireless sensors," in International MultiConference on Systems, Sygnals \& Devices, 2012, pp. 1-4.

[86] T. Beng Lim, N. M. Lee, and B. K. Poh, "Feasibility study on ambient RF energy harvesting for wireless sensor network," 2013 IEEE MTT-S Int. Microw. Work. Ser. RF Wirel. Technol. Biomed. Healthc. Appl., pp. 1-3, 2013.

[87] K. M. Farinholt, G. Park, and C. R. Farrar, "RF Energy Transmission for a Low-Power Wireless Impedance Sensor Node," IEEE Sens. J., vol. 9, no. 7, pp. 793-800, 2009.

[88] K. Kaushik et al., "Experimental demonstration of multi-hop RF energy transfer," in 2013 IEEE 24th Annual International Symposium on Personal, Indoor, and Mobile Radio Communications (PIMRC), 2013, pp. 538-542.

[89] J. P. Olds and W. K. G. Seah, "Design of an active radio frequency powered multi-hop wireless sensor network," in 2012 7th IEEE Conference on Industrial Electronics and Applications (ICIEA), 2012, pp. 1721-1726.

[90] N. Sirdeshpande and V. Udupi, "Data delivery scheme using RFenergy harvesting for wireless sensor networks," in International Conference on Circuits, Communication, Control and Computing, 2014, pp. 285-290.

[91] X. Lu, P. Wang, D. Niyato, D. I. Kim, Z. Han, and C. Engineering, "Wireless Networks with RF Energy Harvesting: A Contemporary Survey," vol. 17, no. 2, pp. 1-34, 2015.

[92] S. Shen, S. Member, C. Chiu, S. Member, and R. D. Murch, "Multiport Pixel Rectenna for Ambient RF Energy Harvesting," vol. 66, no. 2, pp. 644-656, 2018

[93] A. Khemar, A. Kacha, H. Takhedmit, and G. Abib, "Design and experiments of a dual-band rectenna for ambient RF energy harvesting in urban environments," IET Microwaves, Antennas Propag., vol. 12, no. 1, pp. 49-55, 2018.

[94] T. D. Nguyen, J. Y. Khan, and D. T. Ngo, "A Self-Sustainable RF Energy Harvesting Algorithm for WSN-Based IoT Applications," 2017.

[95] J. Ren, J. Hu, D. Zhang, H. Guo, Y. Zhang, and X. S. Shen, "RF Energy Harvesting and Transfer in Cognitive Radio Sensor Networks: Opportunities and Challenges," no. January, pp. 104110, 2018.

[96] X. Zhao, T. Keutel, M. Baldauf, and O. Kanoun, "Energy harvesting for overhead power line monitoring," Int. MultiConference Syst. Sygnals Devices, pp. 1-5, 2012.

[97] R. Moghe, A. R. Iyer, S. Member, F. C. Lambert, S. Member, and D. M. Divan, "A Low-Cost Wireless Voltage Sensor for Monitoring MV / HV Utility Assets," vol. 5, no. 4, pp. 2002-2009, 2014.

[98] C. R. (Rod) Nave, "Electric Field." [Online]. Available: http://hyperphysics.phy-astr.gsu.edu/hbase/electric/elefie.html. [Accessed: 12-Dec-2017].

[99] S. Kang, J. Kim, S. Yang, T. Yun, and H. Kim, "Electric field energy harvesting under actual three-phase $765 \mathrm{kV}$ power transmission lines for wireless sensor node," Electron. Lett., vol. 53 , no. 16 , pp. $1135-1136,2017$

[100] "EMFs Info." [Online]. Available: http://www.emfs.info/sources/overhead/.
[101] M. Temoshok, "Relative Surface voltage Gradients of Grouped Conductors," Trans. Am. Inst. Electr. Eng., vol. 67, no. 2, pp. $1583-1591,1948$.

[102] G. E. Adams, "Voltage gradients on high-voltage lines," Electr. Eng., vol. 74, no. 3, p. 198, 1955.

[103] S. Y. King, "The electric field near bundle conductors," Proc. IEE - Part C Monogr., vol. 106, no. 10, pp. 200-206, 1959.

[104] S. Y. King, "An improved solution for the field near bundle conductors," Electr. Eng. Proc. Inst., vol. 110, no. 6, pp. 1044-1050 1963.

[105] A. Marincu, M. Greconici, and S. Mus, "The Electromagnetic Field Around a High Voltage $400 \mathrm{KV}$ Electrical Overhead Lines and the Influence on the Biological Systems," vol. 18, no. 1, pp. $105-111,2005$

[106] R. K. Z. Sahbudin, "Investigation of Electric Potential and Electromagnetic Field for Overhead High Voltage Power Lines in Malaysia." pp. 1-7, 2010

[107] W. T. B. Kelvin, Reprint of Papers on Electrostatics and Magnetism, no. v. 1. Macmillan, 1872.

[108] P. Hammond, "Electric and magnetic images," Proc. IEE - Part C Monogr., vol. 107, no. 12, pp. 306-313, 1960.

[109] M. P. Sarma and W. Janischewskyj, "Electrostatic Field of a System of Parallel Cylindrical Conductors," IEEE Trans. Power Appar. Syst., vol. PAS-88, no. 7, pp. 1069-1079, 1969.

[110] M. S. Abou-seada and E. Nasser, "Digital Computer Calculation of the Potential and Its Gradient of a Twin Cylindrical Conductor," IEEE Trans. Power Appar. Syst., vol. PAS-88, no. 12, pp. 1802-1814, 1969.

[111] H. Singer, H. Steinbigler, and P. Weiss, "A Charge Simulation Method for the Calculation of High Voltage Fields," IEEE Trans. Power Appar. Syst., vol. PAS-93, no. 5, pp. 1660-1668, 1974.

[112] A. Yializis, E. Kuffel, and P. H. Alexander, "An Optimized Charge Simulation Method for the Calculation of High Voltage Fields," IEEE Trans. Power Appar. Syst., vol. PAS-97, no. 6, pp. 2434-2440, 1978.

[113] H. Qin, S. Lichun, J. Xingliang, X. Rong, Y. Qianfei, and Z. Shikun, "Calculation of Conductors' Surface Electric Field of $\hat{A} \pm 800 \mathrm{kV}$ UHVDC Transmission Lines with Optimized Charge Simulation Method," in 2008 International Conference on High Voltage Engineering and Application, 2008, pp. 362-365.

[114] Q. Li, R. Shuttleworth, G. Zhang, S. M. Rowland, and R. S. Morris, "On calculating surface potential gradient of overhead line conductors," in 2012 IEEE International Symposium on Electrical Insulation, 2012, pp. 540-544.

[115] Q. Li, S. M. Rowland, and R. Shuttleworth, "Calculating the surface potential gradient of overhead line conductors," IEEE Trans. Power Deliv., vol. 30, no. 1, pp. 43-52, 2015.

[116] H. V. A. Smart, R. Moghe, A. R. Iyer, S. Member, F. C. Lambert, and S. Member, "A Low-Cost Electric Field Energy Harvester for an MV/HV Asset-Monitoring Smart Sensor," IEEE Trans. Ind. Appl., vol. 51, no. 2, pp. 1828-1836, 2015.

[117] T. A. Faculty, R. Moghe, and I. P. Fulfillment, "Smart Sensors for Utility Assets," no. August, 2012.

[118] S. Kang, S. Yang, and H. Kim, "Non-intrusive voltage measurement of ac power lines for smart grid system based on electric field energy harvesting,” Electron. Lett., vol. 53, no. 3, pp. $181-183,2017$

[119] J. a. van Schalkwyk and G. P. Hancke, "Energy harvesting for Wireless Sensors from electromagnetic fields around overhead power lines,” 2012 IEEE Int. Symp. Ind. Electron., pp. 1128-1135, 2012.

[120] D. Zhao, L. Li, and D. Dai, "Electric field energy harvesting for on-line condition-monitoring device installed on high-voltage transmission tower," Electron. Lett., vol. 51, no. 21, pp. 1692-1693 2015.

[121] M. J. Moser, T. Bretterklieber, H. Zangl, and G. Brasseur, "Strong and Weak Electric Field Interfering: Capacitive Icing Detection and Capacitive Energy Harvesting on a 220-kV HighVoltage Overhead Power Line,” IEEE Trans. Ind. Electron., vol. 58, no. 7, pp. 2597-2604, 2011

[122] K. Chang, S. Kang, K. Park, S. Shin, H. S. Kim, and H. Kim, "Electric field energy harvesting powered wireless sensors for smart grid," J. Electr. Eng. Technol., vol. 7, no. 1, pp. 75-80, 2012.

[123] J. C. Rodríguez, B. P. Mcgrath, and R. H. Wilkinson, "Maximum Energy Harvesting from Medium Voltage ElectricField Energy using Power Line Insulators," no. October, pp. 1-6, 2014.

[124] X. Zhao, T. Keutel, M. Baldauf, and O. Kanoun, "Power 
Module for a Wireless Sensor Node of a Power," Power, pp. 0-4, 2011.

[125] H. Kim, D. Choi, S. Gong, and K. Park, "Stray electric field energy harvesting technology using MEMS switch from insulated AC power lines," Electron. Lett., vol. 50, no. 17, pp. 1236-1237, 2014.

[126] H. Zangl, T. Bretterklieber, and G. Brasseur, "Energy Harvesting for Online Condition Monitoring of High Voltage Overhead Power Lines," 2008 IEEE Instrum. Meas. Technol. Conf., pp. 1364-1369, 2008.

[127] J. L. Liu, B. Ye, T. W. Zhan, J. H. Feng, J. De Zhang, and X. X. Wang, "Coaxial capacitive dividers for high-voltage pulse measurements in intense electron beam accelerator with water pulse-forming line," IEEE Trans. Instrum. Meas., vol. 58, no. 1, pp. 161-166, 2009. 